\title{
SOLAR COOKERS AND ITS APPLICATION FOR FOOD COOKING IN REMOTE AREAS: REVIEW
}

\author{
Kassem, Talal K., ba and Youssef, M. S.a, \\ Current Address: ${ }^{a}$ Mechanical Engineering Department, College of \\ Engineering,Taif University, Al-Haweiah, P.O. Box 888, Saudi Arabia. \\ Permanent Address: ${ }^{b}$ Mechanical Department, Faculty of Mechanical \& \\ Electrical Engineering, P.O. Box 86, Damascus University, Syria. \\ ${ }^{c}$ Mechanical Engineering Department, Faculty of Engineering, Assiut \\ University, Assiut P. O. Box 71516, Egypt.
}

\section{(Received August 3, 2011 Accepted September13, 2011)}

Cooking is the major necessity for people all over the world. It accounts for a major share of energy consumption in developing countries. Therefore, solar cookers are commonly used in the domestic sector in these countries. The advantages of the use of solar cookers would result in the reduction of the release of $\mathrm{CO} 2$ in the environment. The present work provides the different classification of solar cookers, heat transfer mechanism of cooking, and thermal performance parameters of solar cookers. A literature survey of the different experimental designs of the various solar cookers as well as the different materials used in thermal energy storage has been conducted to determine the thermal performance parameters of each type of the solar cookers. Based on this survey, box type solar cooker has been selected due to its simplicity of handling and operation which coupled with vacuum tube collector. Suitability and application of the present solar cooker system with climate and geographic location of Taif City, Saudi Arabia will be investigated in future research.

KEYWORDS: Solar cookers, Thermal energy storage, Vacuum tube collector, Phase change material, Latent heat, Sensible heat.

\section{INTRODUCTION}

The present research project aims to investigate the feasibility of using solar cookers for food cooking in remote areas in KSA and to provide the industrial community with a database for important parameters and the thermal performance of such type of cookers. The first phase of the project is concerned with reviewing the different types and designs of solar cookers and then selecting the suitable design with climate and geographic conditions of KSA. To meet the objectives of the project, study of the thermal characteristics of the selected design will be addressed in the second phase of the project.

Many methods have been developed to utilize the available solar energy for different end uses. Solar energy is free, environmentally clean, and therefore is recognized as one of the most promising alternative energy resources options. Moreover, solar cooking has proved to be one of the simplest and attractive options for solar energy utilization. Solar cooking has been introduced in 69 countries worldwide 
[1]. The highest numbers of cookers are in India and China, approximately 34,000 in India, and 140,000 in China [1]. In both countries, the solar cooking programs have been promoted by the government. Countries like Pakistan, Kenya, South-Africa, the United States of America (USA) and Switzerland have less than 20,000 solar cookers in each of them $[1,2]$. In some countries the government support solar cooking, for example, the Indian government has offered a subsidy of $33 \%$ on the price of solar cookers for potential buyers. This has resulted in India being the largest marketer of solar cookers in the world [1]. Solar cooking has many advantages such as [3]:

1- no running cost;

2- high nutritional value of the cooked food;

3- high durability.

Cooking energy in urban areas is supplied by fuels such as kerosene, liquid petroleum gas (LPG), Natural Gas, and electrical energy [3]. While, cooking purposes in rural/remote areas mostly use fuels like firewood, agricultural waste, and animal dung. Particularly, in developing countries, there is a critical need for the development of cooking methods based on solar energy. Basically there are different types and designs of solar cookers. For each design of them different performance parameters has been used. Therefore, the following paragraphs will be focused on some types of solar cookers. Before reviewing the various types of solar cookers, the heat transfer mechanism of cooking will be explained first.

\section{HEAT TRANSFER MECHANISM OF COOKING}

Lof [4] explained the mechanism of cooking as: most of the energy required for cooking is consumed during sensible heating period, while, less heat required for physical and chemical changes involved in cooking. The magnitude of energy required for a specific cooking operation is not always known and it depends on the cooking method used (boiling type, frying, roasting). During cooking, $20 \%$ of heat is consumed in bringing food to boiling temperature, $35 \%$ of heat is spent in vaporization of water and $45 \%$ of heat is spent in convection losses [5]. Therefore, insulating the vessel of cooking and also using a lid can considerably reduce the heat losses.

It should be mentioned here that the sensible heating period depends mainly on the material you cook, in other words, once the contents of the cooking vessel have been sensibly heated up to the cooking temperature, the speed of cooking is independent of heat rate. This means that, the differences in time required to cook equal quantities of food are due to different sensible heating periods.

\section{TYPES OF SOLAR COOKERS}

The available solar cookers are mainly classified into two groups. The first group is solar cookers without storage and the second one is solar cookers with storage. More details about each class will be given in the following.

\subsection{Solar Cookers without Storage}

Solar cookers without storage are classified into direct and indirect solar cookers according to the heat transfer mechanism to the cooking vessel [5]. In direct type 
solar cookers, solar radiation is used directly in the cooking process, while, in the indirect solar cookers a heat transfer fluid is used to transfer the heat from the collector to the cooking vessel.

\subsubsection{Direct Solar Cookers}

Direct type cookers are box and concentrating type cookers. Many designs of each type have proposed and tested to investigate the thermal performance parameters for each type. A complete review for both types will be discussed in the following paragraph.

\subsubsection{Box Type Solar Cookers}

Among the direct solar cookers, box type solar cookers are more popular due to their simplicity of handling and operation. Different designs of box type solar cookers are available to enhance the thermal performance of solar cooker. Cooker pot design also helps in improving the thermal performance of the cooker.

A solar box cooker has been designed, constructed and tested by Alozie et al. [1] to investigate its workability of cooking food in most tropical regions where the sun's radiation is abundant. Their results show that the best time to cook with the solar box cooker is between the hours of 11.00 am and 4:00 pm (Nigerian time) on sunny days and is not possible to cook on cloudy or rainy days or at night unless effective solar storage devices are incorporated.

An experimental study was conducted at Irbid city, Jordan by Al-Azab et al. [6] to investigate the thermal performance of box type solar cooker with two different cooking pots (finned and un-finned pots). The box-type solar cooker of Al-Azab et al. is illustrated in Fig. 1. Al-Azab and his coworkers found that the maximum temperature was reached $90{ }^{\circ} \mathrm{C}$ and $98{ }^{\circ} \mathrm{C}$ in un-finned and finned pots, respectively. Moreover, they found that the cooker efficiency can reach $45 \%$ for finned pot and 40 $\%$ for un-finned pot.

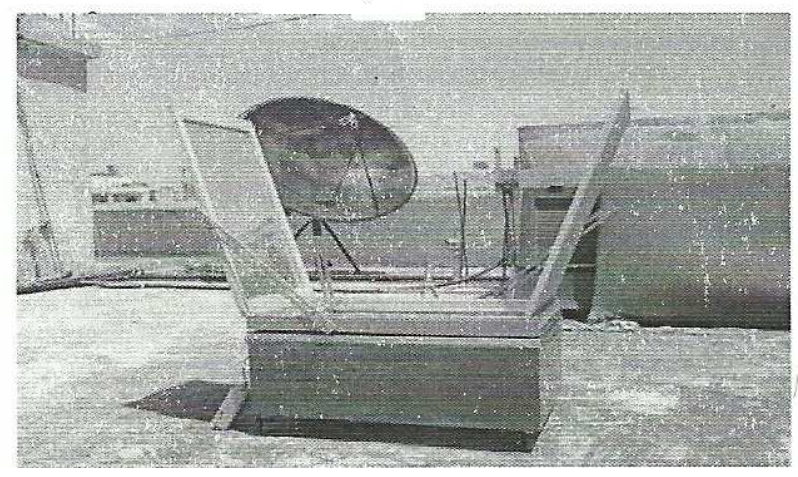

Fig. 1. Box-type solar cooker designed by Al-Azab et al. [6].

Guar et al. [7] designed and fabricated the pot lid in concave shape and carried out water heating test and stagnation test with conventional pot lid and concave shaped lid. They observed that heating time is 15-20 min less in the cooker having pot with concave shaped lid. Also, the stagnation temperature of the cooker with the concave 
shaped lid was greater than the stagnation temperature with the conventional lid by 3 $7^{\circ} \mathrm{C}$.

A comparative experimental study of a box type solar cooker with two different cooking vessels has been carried out by Harmim et al. [8]. The first cooking vessel was conventional and the second one was identical to the first in shape and volume but its external lateral surface provided with fins. The box type solar cooker used by Harmim et al. [8] was of double glazed bottom which allows the absorber to receive solar radiation on its lower side with the help of a parabolic reflector displaced under the cooker. In addition, on its upper side, the absorber was exposed to solar radiation from two glass mirrors hinged to the frame of the upper side of the cooker. The experimental setup of the double exposure solar cooker and the cooking vessels used by Harmim et al. [8] are shown in Figs. 2 and 3. It was experimentally concluded that cooking time can be reduced by using a finned cooking vessel. This reduction is consistent with the increase of the heat transfer surface area by fins attached to the external surface of the cooking vessel.

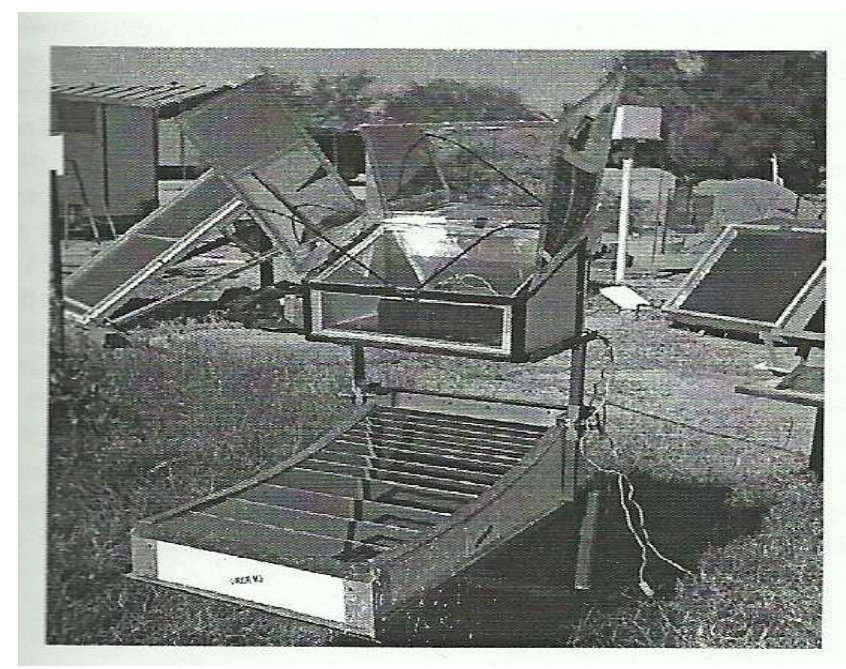

Fig. 2. A photograph of the experimental setup of the double exposure solar cooker of Harmim et al. [8].

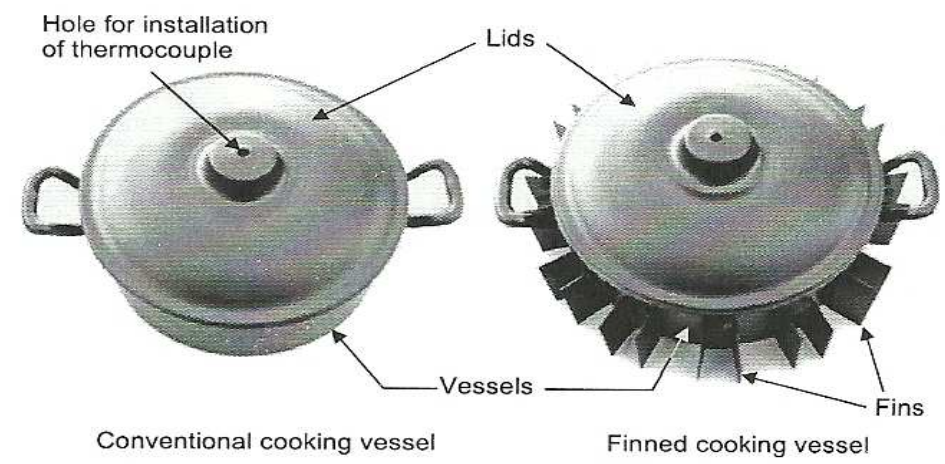

Fig. 3. A photograph of the cooking vessels used by Harmim et al. [8] 
In most recent review article for box type solar cookers, some of the performance parameters and the related test procedures have been reviewed by Lahkar and Samdarshi [9]. They reported that most of the existing performance parameters are largely climate independent and can provide the information about the gradable performance value of the cookers.

Summarizing what is reviewed, one could conclude that, the temperature around $100{ }^{\circ} \mathrm{C}$ is achieved in this type of cookers. This range of temperature is suitable for cooking by boiling. The use of a box type solar cooker is limited because cooking of food is not possible due to frequent clouds in the day and in the evening.

\subsubsection{Concentrating Type Solar Cookers}

In the concentrating solar cookers, the cooking vessel is placed at the focal of a concentrating mirror. According to the mode of concentration of energy, i.e. concentrate light from above or concentrate light from below, there are several designs developed for such type of cookers. The various types of concentrating type cookers are shown in Fig. 4 [5]. Arenas [10] designed, developed and tested a new portable solar kitchen with a large, parabolic solar reflector that folds up into a small volume. Arenas concluded that his solar kitchen provides a portable, inexpensive, and environmentally friendly food heating system.

Concerning the concentrating solar cookers, one may add, such type of cookers works on one or two axis tracking with a concentration ratio up to 50 and temperature up to $300{ }^{\circ} \mathrm{C}$, which is suitable for cooking. Advantages of concentrating cookers include high cooking temperatures, and correspondingly, cooking any types of food and short heat-up times. While, disadvantages are their size, cost, the risk of fires and burns and the inconvenience to adjust the cooker to track the sun [5].

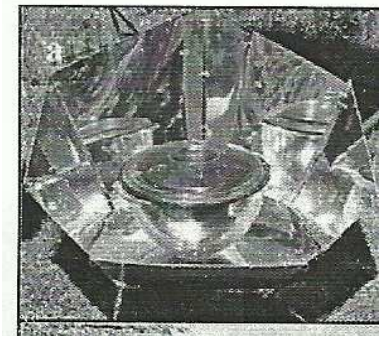

(a) Panel cooker

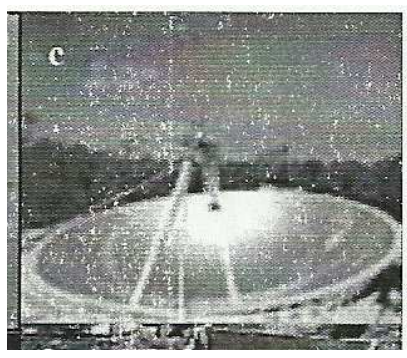

(b) Spherical reflector

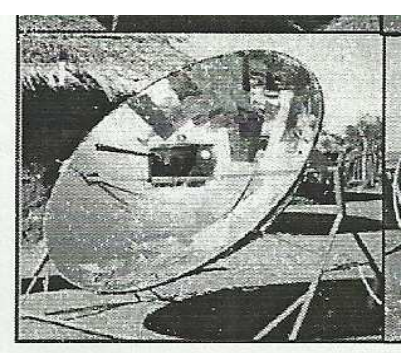

(c) Parabolic reflector

Fig. 4. Concentrating type cookers [5] 


\section{1. 2 Indirect Solar Cookers}

In indirect type solar cookers, the cooking vessel is physically displaced from the collector and correspondingly a heat-transferring medium is required to convey the heat from the collector to the cooking vessel. Three types are categorized under indirect solar cookers, namely; flat plate collector, evacuated tube collector, and concentrating type collector.

\subsubsection{Flat Plate Collector Solar Cookers}

A new flat plate collector solar cooker with one plastic and one glass cover was designed and tested by Schwarzer et al. [11] to study its performance. Figure 5 shows a photograph of the new solar cooker. The preliminary experimental results of Schwarzer and his coworkers showed an increase from 0.35 to approximately 0.4 in the sensible efficiency of the solar collector. Advantages of this cooker are possibility of fast cooking, large vessel cooking volumes and the possibility of indoor cooking [5]. While, the main disadvantage of flat plate collector solar cookers is non-removable vessels which makes cleaning food difficult.

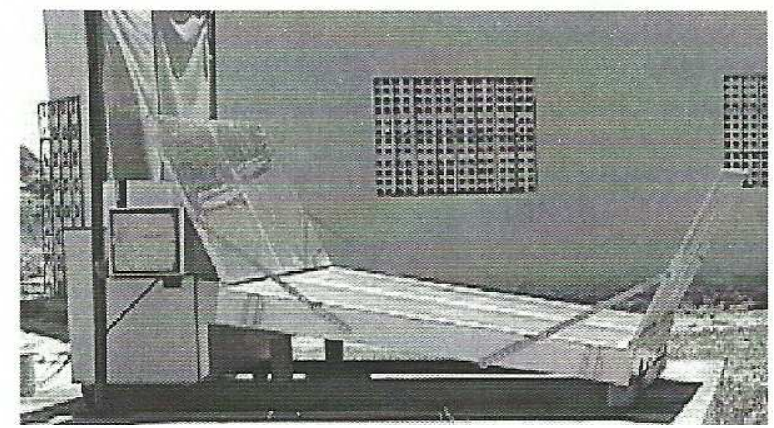

Fig. 5. A photograph of the new flat plate collector solar cooker used by Schwarzer et al. [11].

\subsubsection{Evacuated Tube Collector Solar Cookers}

Solar cooking system based on evacuated tube solar collector has more advantages than box type or concentrator cookers. This system provides high thermal power and temperatures without tracking and allows cooking in the shadow.

Kumar et al. [12] designed a solar pressure cooker based on evacuated tube solar collector. Their system consists of an evacuated tubular solar collector and a pressure cooker which both units are coupled together by heat exchanger. The heat transfer mechanism in Kumar et al.'s system may be explained as: when the incident solar radiation falls onto the collector tubes heats up the working fluid inside these tubes. Correspondingly, the vaporized fluid rises upwards to the heat exchanger and conveys energy by condensation to the water flowing in the secondary loop of the heat exchanger. The condensed working fluid returns back to the collector tubes and the process of heat transfer repeats. In such system, it is observed that, the heat is supplied at higher temperature than normal flat plate collector.

A solar cooking system using vacuum-tube collectors with heat pipes containing a refrigerant as working medium has been fabricated and its performance 
has been analyzed experimentally by Esen [13]. The system mainly consists of three main components, namely, collector, heat pipes, oven section. The collector is made up of six evacuated double-wall (concentric) glass tubes mounted on parabolic concentrating chrome-nickel reflectors. Freon 22, Freon 134a, and Freon 407C were used as working fluids in heat pipes. Figure 6 shows side-view of the solar cooker of an evacuated collector tube with integrated heat pipe used by Esen [13]. Esen demonstrated that cooking times between 27 and 70 min as well as short heat-up times can be obtained with the system used. Nevertheless, the cooking time depends not only on meteorological conditions, but also on the thermophysical properties of the refrigerant used in the heat pipes.

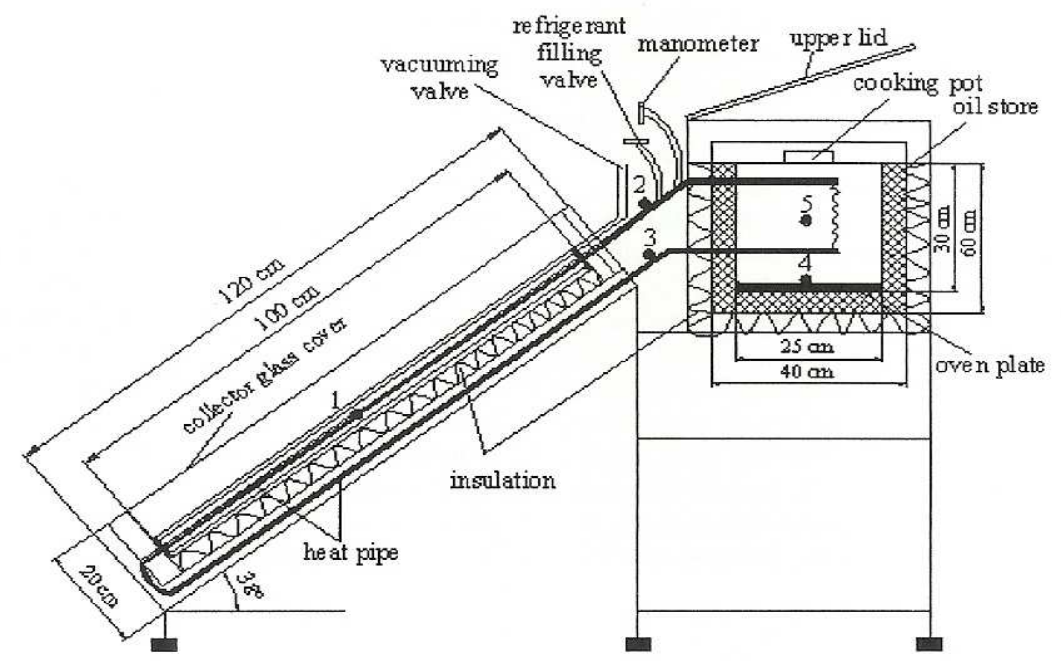

Fig. 6. Side-view of the solar cooker of an evacuated collector tube constructed by Esen [13].

\subsubsection{Concentrating-type Collector Solar Cookers}

In this type of collector either parabolic or spherical shape is used to concentrate the solar radiation. There is a successful solar steam cooking using parabolic concentrators at Tirumala Turupathi Devasthanam in India and solar steam cooking using spherical reflectors at Auroville in Pondichery, India [5]. The first one is considered the world's largest steam cooking system in which generates steam for cooking up to 30,000 meals daily. Regarding the second cooking system at Auroville, the solar bowl is $15 \mathrm{~m}$ in diameter and $7 \mathrm{~m}$ above the ground level. The solar radiation trapped by a hemispherical mirror focuses on a cylindrical boiler in which generates steam at $150{ }^{\circ} \mathrm{C}$ for cooking meals for 1000 people.

\subsection{Solar Cookers with Storage}

Cooking outdoors and impossibility of cooking food in late evening hours are the main problems associated with solar cooking systems. Therefore, thermal energy storage is essentially needed to increase the utility and reliability of the solar cookers. Phase 
change materials (PCM) are materials absorb energy during the heating process as phase change takes place and release energy to the environment in the phase change range during a reverse cooling process. There are three methods for storing thermal energy, namely; latent, sensible, and thermo-chemical heat or cold storage [3]. More details about latent and sensible heat storage materials will be discussed separately in the following paragraphs.

\subsubsection{Solar Cookers with Latent Heat Storage Materials}

The thermal performance of a prototype solar cooker based on an evacuated tube solar collector with phase change material (PCM) storage unit has been investigated by Sharma et al. [14] at Mie, Japan. The PCM storage unit was consisted of two hollow concentric aluminum cylinders in which the space between cylinders was filled with 45 $\mathrm{kg}$ commercial grade erythritol, $\mathrm{C}_{4} \mathrm{H}_{10} \mathrm{O}_{4}$ (melting point $118^{\circ} \mathrm{C}$ ) as a storage medium. Sketch of the solar cooker system used by Sharma et al. [14] is outlined in Fig. 7. Sharma and his coworkers observed that noon cooking did not affect the evening cooking, and evening cooking using PCM heat storage was found to be faster than noon cooking.

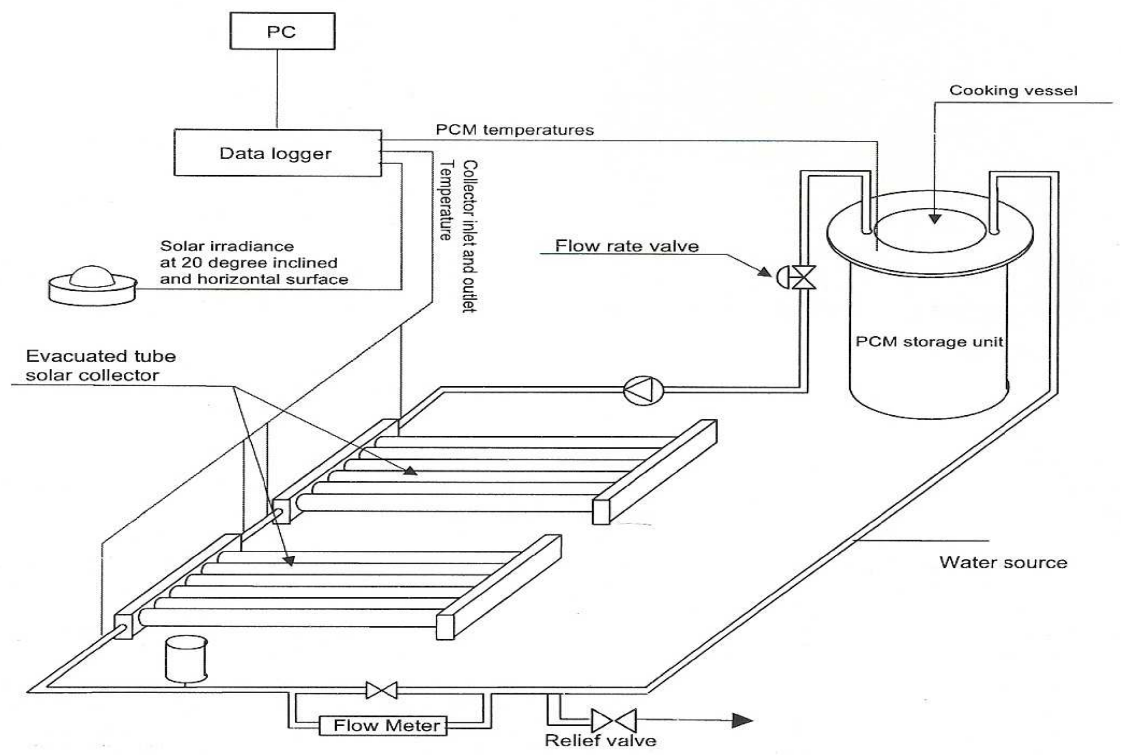

Fig. 7. Outline of the prototype solar cooker based on an evacuated tube solar collector with PCM storage unit used by Sharma et al. [14].

Buddhi et al. [15] tested acetanilide as a PCM with a melting point of $118.9^{\circ} \mathrm{C}$ for night cooking in a box type cooker with three reflectors. Acetanilide was filled in the cylindrical storage unit and it was reported that by using $4.0 \mathrm{~kg}$ of acetanilide, food could be cooked up to 8:00 PM.

\subsubsection{Solar Cookers with Sensible Heat Storage Materials}

In sensible heat storage, thermal energy is stored by raising the temperature of a solid or liquid. Ramadan et al. [16] designed a simple flat-plate solar cooker with focusing 
plane mirrors and energy storage capabilities constructed by the locally available materials in Tanta University, Egypt. They used a jacket of sand around the cooking vessel as heat storage material to improve the cooker performance. Overall energy conversion efficiency up to $28 \%$ has been obtained by Ramadan and his coworkers which was considered the best among other solar cookers in the literature. They also suggested a jacket of salt hydrate $\mathrm{Ba}(\mathrm{OH})_{2} \cdot 8 \mathrm{H}_{2} \mathrm{O}$ around the cooking vessel as storage medium to obtain longer cooking periods.

\section{CONCLUSIONS}

Box-type solar cooker has been adopted for the present research due to its simplicity of handling and operation. This solar system is coupled with vacuum-tube collector and integrated with thermal storage material (copper) to overcome the problems associated with the conventional box-type solar cookers. Feasibility of using such type of cooker under climate and geographic location of Taif City, Saudi Arabia will be investigated in the second phase of this research project.

\section{ACKNOWLEDGEMENTS}

This study is conducted as a part of the research project entitled "Application of Solar Cookers for Food Cooking in Remote Areas in KSA", initiated by Taif University, Saudi Arabia under a contract NO. 1-432-1261. The University is highly acknowledged for the financial support.

\section{REFERENCES}

1. G. A. Alozie, I. M. Mejaha, O. A. Ogungbenro, G. I. Nwandikom, and C. Akujor "Design and construction of a solar box cooker as an alternative in Nigerian kitchens" ISESCO Science and Technology Vision, Vol. 6, Number 9, pp. 57-62, May 2010.

2. Solar Cookers International U. S. A. Newsletter online, The Solar Cooking archives, www.solarcooking.org and www.solarcookers.org, 2004.

3. A. Sharma, C. R. Chen, V. V. S. Murty, and A. Shukla "Solar cooker with latent heat storage systems: a review" Renewable and Sustainable Energy Reviews, Vol. 9, pp. 1599-1605, 2009.

4. G. O. G. Lof "Recent investigation in the use of solar energy for cooking" Solar Energy, Vol. 7, pp. 125-133, 1963.

5. R. M. Muthusivagami, R. Verlaj, and R. Sethumadhavan "Solar cookers with and without thermal storage: A review" Renewable and Sustainable Energy Reviews, Vol. 14, pp. 691-701, 2010.

6. T. A. Al-Azab, M. Q. Al-Odat, and F. M. Al-Hussien " Experimental investigation of a box-type solar cooker with finned pot thermal performance in Jordan" GCREEDER 2009, Amman-Jordan, March $31^{\text {st }}$-April $2^{\text {nd }}, 2009$.

7. A. Gaur, O. P. Singh, S. K. Singh, and G. N. Pandey "Performance study of solar cooker with modified utensil" Renewable Energy, Vol. 18, pp. 121-129, 1999.

8. A. Harmim, M. Boukar, and M. Amar "Experimental study of a double exposure solar cooker with finned cooking vessel" Solar Energy, Vol. 82, pp. 287-289, 2008. 
9. P. J. Lahkar and S. K. Samdarshi "A review of the performance parameters of box type solar cookers and identification of their correlations" Renewable and Sustainable Energy Reviews, Vol. 14, pp. 1615-1621, 2010.

10. J. M. Arenas "Design, development and testing of a portable parabolic solar kitchen" Renewable Energy, Vol. 32, pp. 257-266, 2007.

11. K. Schwarzer, M. E. V. Silva, and L. L. P. Santana "Recent developments of the solar cooking system with or without heat storage for families and institutions" Solar Energy, Vol. 75, pp. 35-41, 2003.

12. R. Kumar, R. S. Adhikari, H. P. Carg, and A. Kumar "Thermal performance of a solar pressure cooker based on evacuated tube solar collector" Applied Thermal Engineering, Vol. 21, pp. 1699-1705, 2001.

13. M. Esen "Thermal performance of a solar cooker integrated vacuum-tube collector with heat pipes containing different refrigerants" Solar Energy, Vol. 76, pp. 751757, 2004.

14. S. D. Sharma, T. Iwata, H. Kitano, and K. Sagara "Thermal performance of a solar cooker based on an evacuated tube solar colletor with a PCM storage unit" Solar Energy, Vol. 78, pp. 416-426, 2005.

15. D. Buddhi, S. D. sharma, and A. Sharma "Thermal performance evaluation of a latent heat storage unit for late evening cooking in a solar cooker having three reflectors" Energy Conversion and Management, Vol. 44, pp. 809-817, 2003.

16. M. R. I. Ramadan, S. Aboul-Enein, and A. A. El-sebaii "A model of an improved low cost indoor solar cooker in Tanta" Solar and Wind Technology, Vol. 5, pp. 387-393, 1998.

\section{الأفران الشمسية وأستخداماتها في طهي الطعام في المناطق النائية:

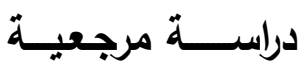

يعتبر طهى الطعام من أهم ضروريات الحياة لكافة البشر ، إذ يعتبر القاسم الأعظم لإستهلاك الطاقة فى

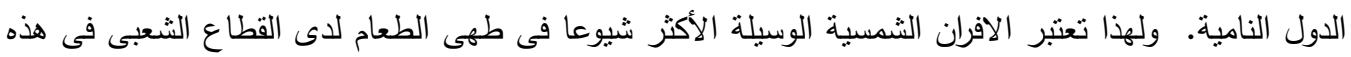
البلدان. من أهم ما يميز الأفران الثمسية أنها صديقة للبيئة وتساعد على تقليل إنبعاثات غاز ثانئ ثانى أكسيد

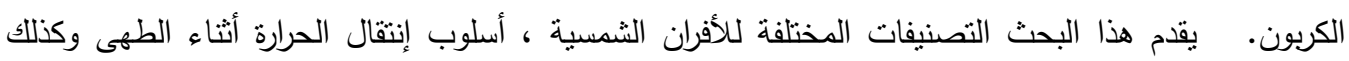
متغيرات الأداء الحرارى للأفران الثمسية المختلفة. تم فى هذا البحث عمل مسح مرجعى شامل للأبحاث المنشورة للتصميمات المعملية المختلفة للأفران الثمسية المختلفة وكذلك المواد المختلفة المستخدمة فى نخزين الطاقة الحرارية وذلك بقصد تحديد متغيرات الأداء الحرارى لكل نوع من الافران الثمسية. بناءا على هذا المسح تم أختيار فرن شمسى صندوقى الثكل لبساطة التعامل والنتغيل بحيث بعمل مع مجمع شمسى من الأنابيب المفرغة. مدى ملائمة وتطبيق عمل جهاز الفرن الثمسى المقترح فى ظل الظروف المناخية والجغرافية لمدينة الطائف بالمملكة العربية السعودية سوف يترك للمرحلة القادمة لهذا المشروع • 